\title{
Factor VIII ectopically targeted to platelets is therapeutic in hemophilia $A$ with high-titer inhibitory antibodies
}

\author{
Qizhen Shi, ${ }^{1,2,3}$ David A. Wilcox, ${ }^{1,2,3}$ Scot A. Fahs, ${ }^{1}$ Hartmut Weiler, ${ }^{1,2}$ Clive W. Wells, ${ }^{2}$ \\ Brian C. Cooley, ${ }^{2}$ Drashti Desai, ${ }^{1,2,3}$ Patricia A. Morateck, ${ }^{1}$ Jack Gorski, ${ }^{1,2}$ \\ and Robert R. Montgomery ${ }^{1,2,3}$
}

${ }^{1}$ Blood Research Institute, BloodCenter of Wisconsin, Milwaukee, Wisconsin, USA. ${ }^{2}$ Departments of Pediatrics, Physiology, Microbiology, and Orthopedics, Medical College of Wisconsin, Milwaukee, Wisconsin, USA. ${ }^{3}$ Children's Research Institute, Children's Hospital of Wisconsin, Milwaukee, Wisconsin, USA.

\begin{abstract}
Inhibitory immune response to exogenously infused factor VIII (FVIII) is a major complication in the treatment of hemophilia A. Generation of such inhibitors has the potential to disrupt gene therapy for hemophilia A. We explore what we believe to be a novel approach to overcome this shortcoming. Human B-domain-deleted FVIII (hBDDFVIII) was expressed under the control of the platelet-specific $\alpha$ IIb promoter in platelets of hemophilic (FVIII ${ }^{\text {null }}$ ) mice to create $2 \mathrm{bF8}^{\text {trans }}$ mice. The FVIII transgene product was stored in platelets and released at the site of platelet activation. In spite of the lack of FVIII in the plasma of $2 \mathbf{b F}^{\text {trans }}$ mice, the bleeding phenotype of FVIII ${ }^{\text {null }}$ mice was corrected. More importantly, the bleeding phenotype was corrected in the presence of high inhibitory antibody titers introduced into the mice by infusion or by spleen cell transfer from recombinant hBDDFVIII-immunized mice. Our results demonstrate that this approach to the targeted expression of FVIII in platelets has the potential to correct hemophilia A, even in the presence of inhibitory immune responses to infused FVIII.
\end{abstract}

\section{Introduction}

Monogenic diseases, characterized by the loss of a specific plasma protein, are currently treated by repetitive replacement therapy and are choice candidates amenable to gene therapy. Hemophilia A, a severe congenital bleeding disorder caused by the loss of clotting factor VIII (FVIII) (1), is a prototype of such monogenic diseases. Currently, hemophilia A is treated by infusion of recombinant or plasma-derived FVIII (2). However, $25-30 \%$ of patients develop antibodies (FVIII inhibitors) that selectively inactivate the clotting activity of FVIII and negate its therapeutic efficacy (3). Hemophilia $\mathrm{A}$ is considered a strong candidate for gene therapy because the therapeutic window is broad and even a minimal plasma level of plasma FVIII is clinically advantageous. The development of inhibitory antibodies to the FVIII transgene product in plasma remains a significant barrier to some patient candidates. Many groups have developed various strategies for directing FVIII synthesis (4-15), although inadequacies of gene delivery and expression and inhibitor formation remain clinical problems $(7,16-18)$.

The approach we investigated, which we believe to be novel, is based on the hypothesis that targeting the production of FVIII to a secreting cell type that acts in the immediate vicinity of sites where FVIII is needed could overcome the presence of inhibitory antibodies. Furthermore, by sequestering the FVIII, the generation of antibodies in naive individuals might be prevented or at least rendered less relevant.

Nonstandard abbreviations used: $2 \mathrm{bF} 8$, human $\alpha \mathrm{IIb}$ promoter-driven hBDDFVIII; $2 \mathrm{bF}^{\text {trans }}, \mathrm{FVIII}^{\text {null }}$ mouse with $2 \mathrm{bF} 8$ transgene expression; $2 \mathrm{bF}^{\mathrm{tg}+/-}$, heterozygous 2bF8 ${ }^{\text {trans }} ; 2 \mathrm{bF}^{\mathrm{tg}+/+}$, homozygous $2 \mathrm{bF}^{\text {trans; }}$ BMT, bone marrow transplantation; BU, Bethesda units; CHAPS, 3-[(3-Cholamidopropyl)dimethylammonio]-1-propanesulfonate; FVIII, factor VIII; FVIII:C, FVIII activity; FVIII ${ }^{\text {null }}$, FVIII-deficient (mouse); GP, glycoprotein; hBDDFVIII, human B-domain-deleted FVIII; rhBDDFVIII, recombinant hBDDFVIII; VWFnull, VWF-deficient (mouse).

Conflict of interest: The authors have declared that no conflict of interest exists. Citation for this article: J. Clin. Invest. 116:1974-1982 (2006). doi:10.1172/JCI28416
The feasibility of such an approach is supported by the fact that in plasma, VWF serves as the obligate carrier protein for FVIII and protects it from protease degradation and rapid clearance $(1,19$, 20 ). We have previously demonstrated that coexpression of FVIII in a cell that stores VWF results in the costorage, and release, of FVIII $(4,21)$. More specifically, directing FVIII expression to megakaryocytes results in storage of FVIII with VWF in the $\alpha$-granules of platelets $(22,23)$. A megakaryocytic, lineage-specific promoter would direct FVIII expression only to that blood cell lineage where VWF is normally endogenously synthesized and stored $(20,24)$. Poncz and coworkers have reported that expressing FVIII in platelets under control of the glycoprotein Ib $\alpha$ (GPIb $\alpha$ ) promoter in FVIII-deficient (FVIII ${ }^{\text {null }}$ ) mice can ameliorate bleeding in a FVIII ${ }^{\text {null }}$ mouse model (9). In addition to platelets, GPIb $\alpha$ expression has been reportedly synthesized in endothelial (25-27) and breast tumor cells (28). Thus, we chose the platelet-specific GPIIb gene promoter (the $\alpha \mathrm{IIb}$ promoter) that has been demonstrated to direct megakaryocyte-specific gene transcription (22, 29-37).

In the current study, we used the $\alpha \mathrm{IIb}$ promoter to direct FVIII expression and determined (a) that transgenic platelet-expressed and stored FVIII effectively protected FVIII ${ }^{\text {null }}$ mice from bleeding, (b) that this protection was transferable into FVIIInull recipients via transgenic platelet transfusion, and (c) that this therapeutic efficacy was maintained even in the presence of high-titer inhibitory antibodies to FVIII. This approach may be promising for hemophilia treatment as well as other conditions where the missing protein can be targeted directly to the site of desired activity. Furthermore, the presence of preexisting inhibitory antibodies might not be a contraindication for such an approach.

\section{Results}

Transgenic expression of FVIII in platelets. We generated transgenic mice expressing human B-domain-deleted FVIII (hBDDFVIII) 
A
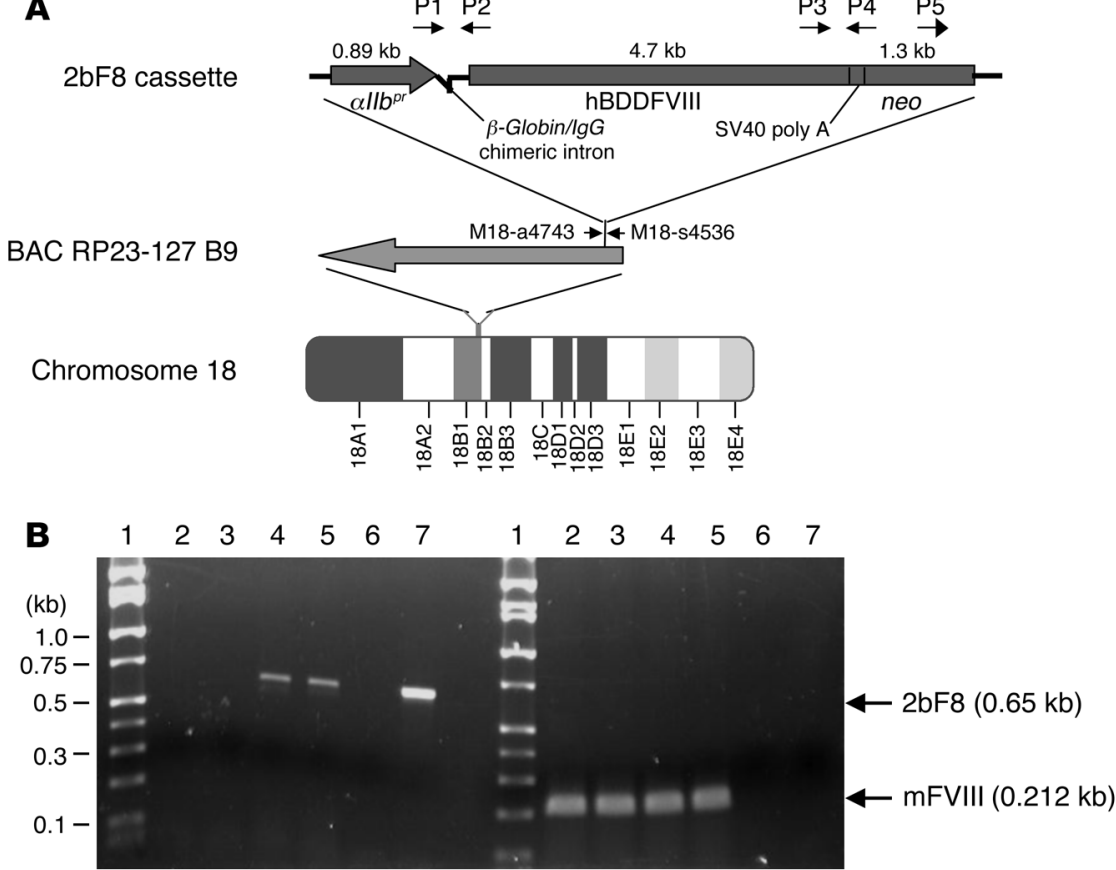

\section{Figure 1}

Construct of the $2 \mathrm{bF} 8$ transgene as well as genetic and integration site analysis. (A) Schematic diagram of transgene construct and insertion location. Construct of the 2bF8 cassette (from $5^{\prime}$ to $3^{\prime}$ ): the human GPIIb gene promoter ( $\alpha \mathrm{llb}^{\mathrm{pr}}$ ), chimeric intron, hBDDFVIII, SV40 poly $\mathrm{A}$, and neomycin resistance. Insertion of $2 \mathrm{bF} 8$ transgene was in the $\mathrm{B} 1$ band of chromosome 18. (B) PCR analysis showed that $2 \mathrm{bF} 8$ transgene was detected in $2 \mathrm{bF} 8^{\text {trans }}$ and FVIIInull mice after receiving BMT from $2 \mathrm{bF}{ }^{\text {trans }}$ mouse and 3 weeks' reconstitution. Lane 1, DNA marker; lane 2, WT; lane 3, FVIIInull; lane 4, 2bF8trans; lane 5, FVIIInull following BMT (recipient); lane 6, $\mathrm{H}_{2} \mathrm{O}$; lane $7,2 \mathrm{bF} 8$ vector. DNA was purified from peripheral blood, and transgene was amplified with primers P1 and P2 (left panel; see Table 1). Mouse FVIII exon 4 (mFVIII), which is not disrupted in FVIIInull mice, was amplified as an internal control (right panel). using the 7.6-kb $P v u \mathrm{I} / B \sin B \mathrm{I}$ insert of the human $\alpha \mathrm{IIb}$ promoterdriven hBDDFVIII ( $2 \mathrm{bF} 8$ ) construct (Figure 1A). Germline transmission was established, and transgene-positive offspring were mated with FVIIInull mice to generate mice that express the $2 \mathrm{bF} 8$ transgene without expression of normal mouse FVIII ( $2 \mathrm{bF}{ }^{\text {trans }}$ mice). A single $2 \mathrm{bF} 8$ transgene insertion site was determined by DNA Walking PCR and demonstrated that the sequence flanking the 2 bF8 transgene was identical to BAC RP23-127 B9 located in the $\mathrm{B} 1$ band of chromosome 18 . The integration site, between bases 4667 and 4668 of this BAC clone, is in a PB1D10 type repeat sequence (Figure $1 \mathrm{~A})$.

Demonstrating platelet-specific expression of hBDDFVIII. It has been shown that the human $\alpha I I b$ promoter confines transgene expression to the platelet lineage (35-37). Immunofluorescent microscopy was performed to confirm the expression of recombinant FVIII within platelets (Figure 2, A-F). FVIII protein was detected in the platelets of $2 \mathrm{bF} 8^{\text {trans }}$ mice and colocalized with mouse VWF (Figure 2F). EM further confirmed that FVIII is stored together with VWF in $\alpha$-granules in the platelets of $2 \mathrm{bF} 8^{\text {trans }}$ mice (Figure 2, I-K). FVIII was absent from platelets of FVIII ${ }^{\text {null }}$ control mice, although a normal distribution of VWF was observed (Figure 2, A-C, G, and H). In contrast, FVIII was not detected in mononuclear cells from transgenic mice by confocal microscopy (Figure 2, L-Q). Similarly, FVIII activity (FVIII:C) was not detected in mononuclear cell lysates from either $2 \mathrm{bF}{ }^{\text {trans }}$, WT, or FVIII ${ }^{\text {null }}$ mice (Figure $2 \mathrm{R}$ ). In addition, platelet-specific expression was maintained after bone marrow transplantation (BMT) of FVIII ${ }^{\text {null }}$ mice with $2 \mathrm{bF} 8^{\text {trans }}$ bone marrow (see below).

Platelet localization of transgene expression and its angmentation by VWF. Functional FVIII:C was measured in mouse plasma and in platelet lysates. The FVIII:C measured in WT mouse plasma was $1.20 \pm 0.12$ $\mathrm{U} / \mathrm{ml}$ when assayed against a recombinant hBDDFVIII (rhBDDFVIII) standard. Plasma FVIII:C was undetectable in FVIII ${ }^{\text {null }}$ mice, as expected; however, it was also not detected in the plasma of $2 \mathrm{bF} 8^{\text {trans }}$ mice (Figure $3 \mathrm{~A}$ ). FVIII is normally not expressed in platelets. FVIII:C was functional when added to WT platelet lysate (Figure 3B), but was not detected in platelet lysate from either WT or FVIII ${ }^{\text {null }}$ control mice (Figure $2 \mathrm{R}$ and Figure $3 \mathrm{C}$ ). However, functional FVIII:C was detected in platelet lysates from $2 \mathrm{bF}^{\text {trans }}$ mice at $0.74 \pm 0.13 \mathrm{mU} / 10^{8}$ platelets in heterozygous $\left(2 \mathrm{bF}^{\mathrm{tg}^{+/-}}\right)$and $1.41 \pm 0.25 \mathrm{mU} / 10^{8}$ platelets in homozygous $\left(2 \mathrm{bF}^{\mathrm{tg}+/+}\right) 2 \mathrm{bF} 8^{\text {trans }}$ mice (Figure $3 \mathrm{C}$ ). Assuming the volume of plasma is $50 \%$ of whole blood and that the platelet count is $1 \times 10^{9} / \mathrm{ml}$, these amounts of platelet FVIII would correspond to approximately $1.23 \%$ and $2.35 \%$ of FVIII:C, respectively, in whole blood of normal mice. The detection limit of this assay was $0.07 \mathrm{mU} / 10^{8}$ platelets. Alternatively, the stored FVIII could be measured following agonist-induced platelet activation (epinephrine, ADP, and the thrombin receptor activation peptide). The amount released, $0.61 \pm 0.18 \mathrm{mU}$ FVIII:C $/ 10^{8}$ platelets, was similar to the amount measured in $2 \mathrm{bF} 8^{\text {trans }}$ platelet lysate.

Since plasma VWF is required for sustaining normal plasma FVIII levels, we determined whether VWF was similarly required to sustain transgenic FVIII in platelets. The $2 \mathrm{bF} 8$ transgene was bred into VWF-deficient (VWFnull) mice so that the 2bF8 transgene was expressed on a double-knockout background (FVIIInullVWFnull). The levels of platelet FVIII:C were found to be significantly decreased in $2 \mathrm{bF}^{\text {trans }} V W F^{\text {null }}$ mice compared with those of the respective $2 \mathrm{bF}^{\text {trans }} \mathrm{VWF}^{+/+}$mice $\left(2 \mathrm{bF}^{\text {tg }+/-V W F}{ }^{\text {null }}, 0.39 \pm 0.18 \mathrm{mU} / 10^{8}\right.$ platelets; $2 \mathrm{bF}^{\mathrm{tg}+/+} \mathrm{VWF}^{\mathrm{null}}, 0.81 \pm 0.22 \mathrm{mU} / 10^{8}$ platelets; $P<0.001$; Figure 3C). While platelet FVIII was expressed in the absence of VWF, the presence of platelet VWF either enhanced storage or protected FVIII, resulting in higher levels of FVIII:C in platelets. These results demonstrate that FVIII transgene driven by the $\alpha$ IIb promoter is present in platelets, is functional, is enhanced by VWF, and is released following platelet activation, but does not result in measurable levels in mouse plasma.

Platelets expressing hBDDFVIII correct the bleeding phenotype of FVIII ${ }^{\text {null }}$ mice. Mice expressing the $2 \mathrm{bF} 8$ transgene in platelets but lacking endogenous mouse FVIII were tested for correction of the hemophilia A phenotype. To assess correction of the FVIIInull 

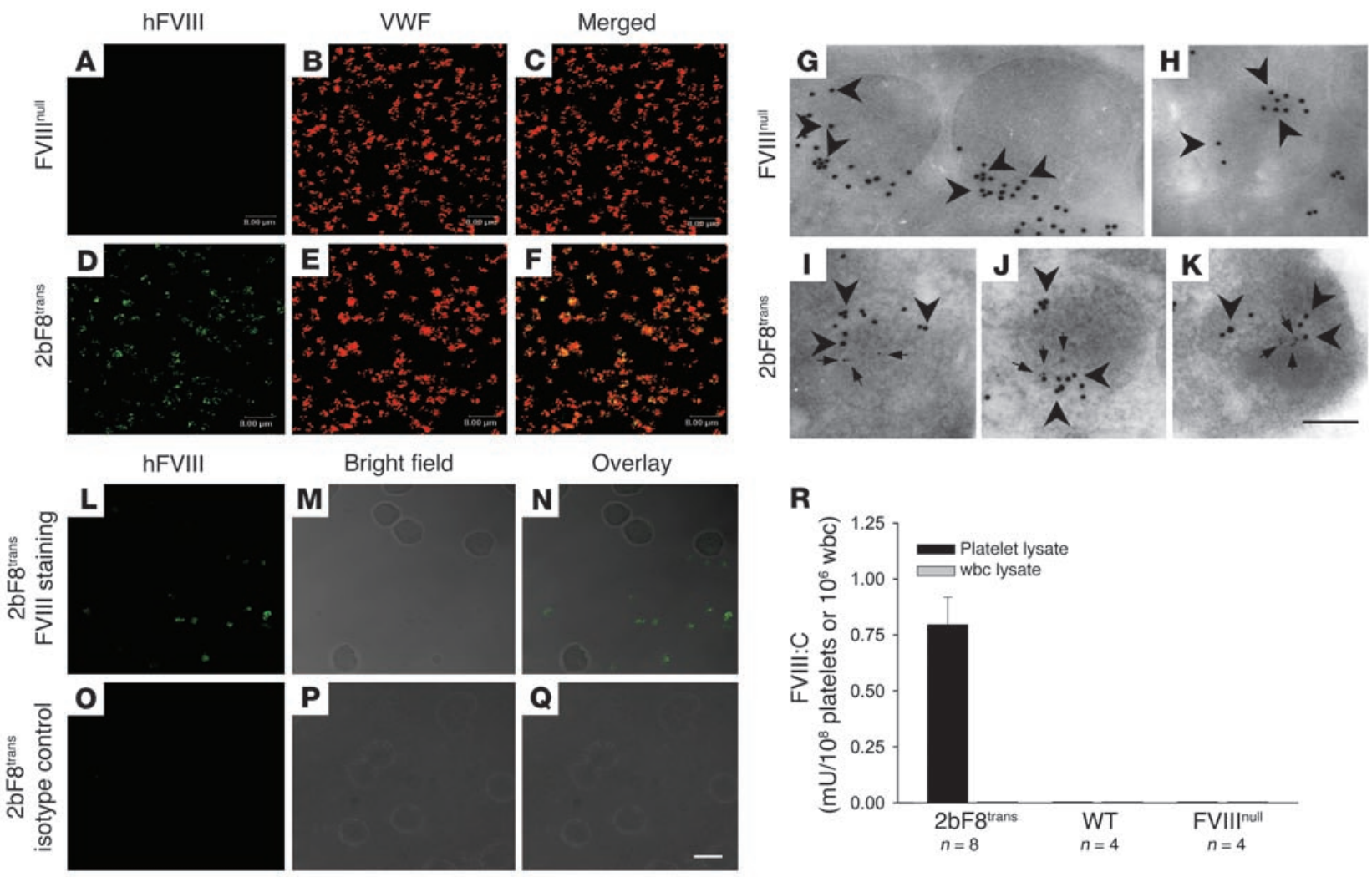

Figure 2

Platelet-specific expression of FVIII. (A-F) Localization of transgene protein expression was determined by immunofluorescent microscopy. Isolated platelets from FVIIInull $(\mathbf{A}-\mathbf{C})$ and $2 \mathrm{bF} 8^{\text {trans }}$ mice $(\mathbf{D}-\mathbf{F})$ were immunostained for either human FVIII (hFVIII; $\mathbf{A}$ and $\left.\mathbf{D}\right)$ or mouse VWF (B and $\mathbf{E})$. The 2 images were merged in $\mathbf{C}$ and $\mathbf{F}$, showing that in the platelets of 2 bF ${ }^{\text {trans }}$ mice (F) VWF and FVIII were colocalized (yellow). (G-K) Colocalization of human FVIII and mouse VWF was confirmed by electron microscopy. Isolated platelets from FVIIInull mice $(\mathbf{G}$ and $\mathbf{H})$ and $2 \mathrm{bF} 8^{\text {trans }}$ mice (I-K) were immunostained for human and mouse VWF. FVIII was probed with $5 \mathrm{~nm}$ colloidal gold and VWF with $10 \mathrm{~nm}$ colloidal gold; representative gold particles are indicated by arrows and arrowheads, respectively. The results show FVIII was stored together with VWF in platelet $\alpha$-granules of $2 \mathrm{bF} 8^{\text {trans }}$ mice (I-K). ( $\left.\mathbf{L}-\mathbf{Q}\right)$ Confocal microscopy detected no human FVIII in mononuclear cells from transgenic mice. Isolated platelets and mononuclear cells from $2 \mathrm{bF} \mathrm{g}^{\text {trans }}$ mice were immunostained for human FVIII. Nonspecific isotype-matched primary Ab was used for background staining. (R) Quantitative evaluation of FVIII:C levels in mouse mononuclear cell lysates. Platelets and mononuclear cells were isolated and lysed in 0.5\% CHAPS. FVIII:C in lysates was determined by chromogenic assay. No FVIII:C was detected in mononuclear cell lysates from either $2 b F 8^{\text {trans }}$ or control mice (i.e., WT and FVIIInull mice). FVIII:C was detected in platelet lysates from $2 b F 8^{\text {trans }}$ mice. Scale bars: $8 \mu \mathrm{m}(\mathbf{A}-\mathbf{F}$ and $\mathbf{L}-\mathbf{Q}) ; 0.2 \mu \mathrm{m}(\mathbf{G}-\mathbf{K})$.

coagulation defect, we determined the ability to clot and survive after inducing a minor wound by tail clipping. All $182 \mathrm{bF} 8^{\text {trans }}$ mice survived the tail clip test, while none of nine FVIIInull mice were able to clot and survive tail clipping (Figure 3D).

In order to confirm that the benefit of $2 \mathrm{bF} 8$ expression resides within hematopoietic cells alone, bone marrow mononuclear cells from heterozygous $2 \mathrm{bF} 8^{\text {trans }}$ mice was transplanted into lethally irradiated FVIIInull mice. Three weeks after transplantation, the presence of the $2 \mathrm{bF} 8$ transgene in recipients was confirmed by PCR (Figure 1B). FVIII:C was not detectable in the plasma of recipients, but $0.72 \pm 0.12 \mathrm{mU} / 10^{8}$ platelets was measured in platelet lysates. There was no significant difference between the FVIII:C in platelet lysates of recipients and donors $(P=0.73$; Figure $3 C)$. Furthermore, sequential BMT into a second generation of recipients maintained similar levels of FVIII:C in their platelets as determined by platelet lysate FVIII:C assay, thereby demonstrating long-term reconstitution. All recipients (from 4 separate BMT experiments) survived tail clipping (Figure 3D). In the control group, none of 4 recipients that received bone marrow mononuclear cells from FVIII ${ }^{\text {null }}$ mice had FVIII:C in their platelet lysate and none had phenotype correction. To confirm that this beneficial effect is derived from platelets, we transfused different proportions of washed heterozygous $2 \mathrm{bF}^{\text {trans }}$ platelets into FVIIInull mice and then performed the tail clip survival test. All 7 FVIII ${ }^{\text {null }}$ mice that were infused with $2 \mathrm{bF}^{\mathrm{tg}+/}$ platelets to achieve final levels of $30 \%$ of total platelets survived tail clipping, while 5 of 6 FVIII null mice infused with the same number of platelets from WT mice did not survive tail clipping. Infusion of FVIIInull platelets had no effect on survival (Figure 3E). When lower doses (10-20\%) of $2 \mathrm{bF}^{\mathrm{tg}+/-}$ platelets were infused, some benefit was demonstrated. Of the 6 FVIII $^{\text {null }}$ mice infused with $2 \mathrm{bF}^{\mathrm{tg}+/-}$ platelets to achieve final levels of $20 \%$, five survived tail clipping, and 3 of 6 mice infused to $10 \%$ of total platelets survived. These data demonstrate that platelet FVIII is sufficient to correct the hemophilic A phenotype in mice. In previous studies from our laboratory, greater than $50 \%$ transduction efficiency can be demonstrated using lentivirally mediated gene therapy for platelet 
A

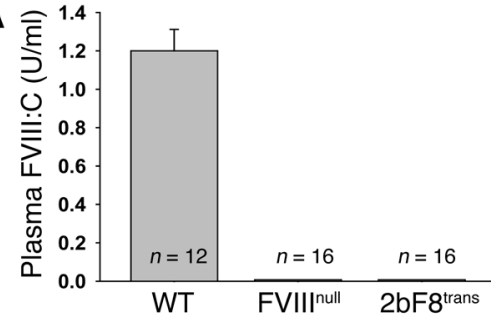

B

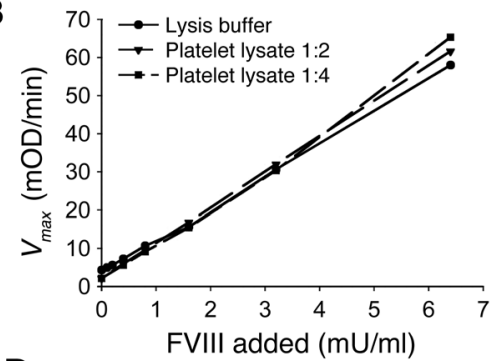

D

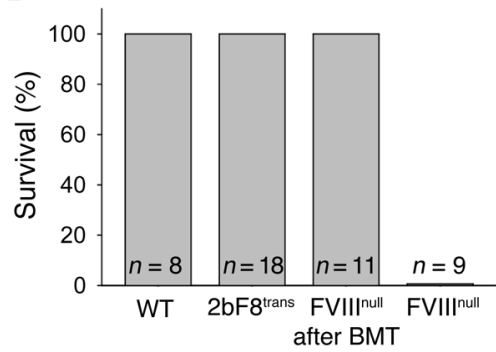

C

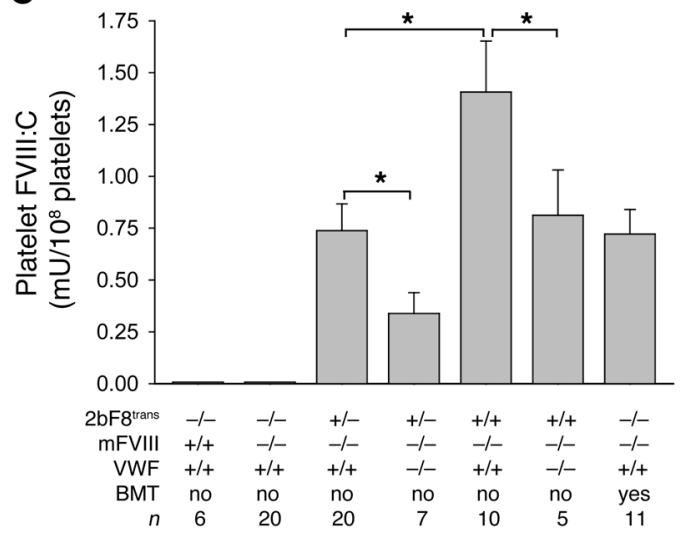

E

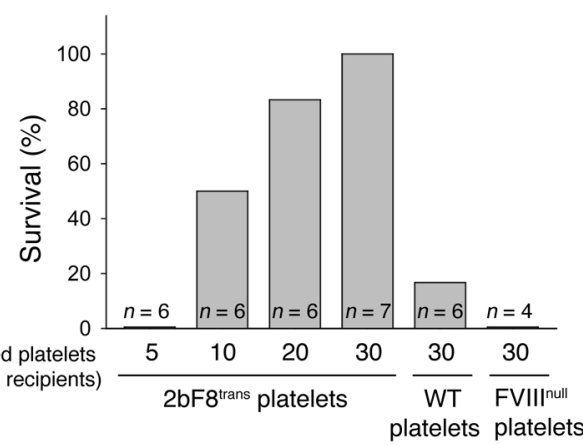

Figure 3

Platelet-derived FVIII can function in hemostasis. (A) Quantitative evaluation of FVIII:C levels in mouse plasma by chromogenic assay. No FVIII:C was detected in the plasma of FVIIInull and 2bF8 trans mice. (B) Platelet lysate added to dilutions of FVIII did not alter level of FVIII:C as measured by chromogenic assay. (C) Quantitative evaluation of FVIII:C levels in mouse platelet lysates. Platelets were isolated and lysed in $0.5 \%$ CHAPS. FVIII:C in lysates was quantitated by chromogenic assay. FVIII:C was detected in platelet lysates from $2 \mathrm{bF} 8^{\text {trans }}$ mice and bone marrow recipients from $2 \mathrm{bF} 8^{\mathrm{tg}+/}$ mice. Platelet FVIII:C was significantly increased in $2 \mathrm{bF}^{\mathrm{tg}+/+}$ mice compared with $2 \mathrm{bF} 8^{\mathrm{tg}+/}$ mice. FVIII:C was significantly decreased in $2 \mathrm{bF} 8^{\text {trans }} \mathrm{VWFnull}$ mice. ${ }^{*} P<0.001$. (D) Tail clip survival test assessing phenotypic correction of hemophilia A mice. All $2 b F 8^{\text {trans }}$ mice and their bone marrow recipients survived tail clipping. (E) Tail clip survival test assessing the beneficial effect of transgenic platelets. Different proportions of washed platelets were transfused into FVIIInull mice, which was followed by tail clipping. All FVIIInull mice that were infused with $2 \mathrm{bF} 8^{\mathrm{tg}+/}$ platelets to a final level of $30 \%$ of total platelets survived tail clipping.

GP deficiencies (GPIIIa, ref. 37, or GPIb $\alpha$, ref. 38). Thus achieving transgene expression in $30 \%$ of platelets would be obtainable through gene therapy of autologous hematopoietic stem cells.

Correction of hemophilic phenotype in FVIII null mice occurs even in the presence of high-titer FVIII inhibitors. To explore whether platelet-derived FVIII can maintain therapeutic effectiveness in the presence of FVIII inhibitors, we used 3 strategies: (a) an acute model infusing plasma from highly immunized FVIII ${ }^{\text {null }}$ mice; (b) a chronic model using transplantation of spleen cells from immunized FVIIInull mice into sublethally irradiated $2 \mathrm{bF} 8$ transgenic mice; and (c) active immunization of $2 \mathrm{bF} 8^{\text {trans }}$ mice with rhBDDFVIII with adjuvant. The inhibitor titer was determined by a modified Bethesda assay (39) and expressed in Bethesda units (BU). Plasma inhibitor titers after infusion studies were confirmed by Bethesda assay.

FVIIInull mice infused with rhBDDFVIII to a plasma level of 0.02 $\mathrm{U} / \mathrm{ml}$ had normal survival after tail clipping. Of the 6 FVIII null mice infused to a Bethesda titer of $2.5 \mathrm{BU} / \mathrm{ml}$ with inhibitory plasma from immunized FVIIInull mice and then given $0.02 \mathrm{U} / \mathrm{ml}$ rhBDDFVIII, only 2 survived tail clipping. In mice infused to a level of 25 or $250 \mathrm{BU} / \mathrm{ml}, 0$ of 12 mice infused with $0.02 \mathrm{U} / \mathrm{ml}$ survived tail clipping (Figure 4A).

In order to determine the effect of inhibitory antibodies in $2 \mathrm{bF}^{\text {trans }}$ mice, the transgenic mice were administered plasma from immunized FVIIInull mice. Immunization of FVIII ${ }^{\text {null }}$ mice produced inhibitor titers as high as $100,000 \mathrm{BU} / \mathrm{ml}$ after $3 \mathrm{immu}-$ nization doses of rhBDDFVIII administrated with adjuvant by i.p. injection. All $162 \mathrm{bF} 8^{\text {trans }}$ mice infused to a final concentration of either 2.5 or $25 \mathrm{BU} / \mathrm{ml}$ with inhibitory plasma from immunized FVIIInull mice survived tail clipping, and 7 of 8 mice infused to $250 \mathrm{BU} / \mathrm{ml}$ survived tail clipping (Figure 4B).

In spleen cell transplantation experiments, all mice developed high titers of inhibitory antibody following reconstitution. In the presence of 5,000-50,000 BU/ml, 5 of 7 transgenic mice survived tail clipping, and 3 of 5 transgenic mice survived tail clipping in spite of an inhibitor titer greater than $50,000 \mathrm{BU} / \mathrm{ml}$ (Figure 4C). The platelet count in recipients following reconstitution $(0.74 \pm$ $\left.0.20 \times 10^{9} / \mathrm{ml} ; n=8\right)$ was not significantly different from the pretransplantation platelet count $\left(0.69 \pm 0.20 \times 10^{9} / \mathrm{ml} ; P=0.62\right)$.

We followed platelet counts in 2 recipients for 6 months, and the platelet counts were not decreased, yet their inhibitor titers remained greater than $50,000 \mathrm{BU} / \mathrm{ml}$. This implies that circulating FVIII inhibitory antibodies in plasma do not interfere with normal platelet production or survival in these mice.

FVIII:C was not detected in the plasma of WT mice receiving spleen cells from immunized FVIIInull mice, although their plasma FVIII:C was normal before receiving immunized spleen cells, and only 2 of 7 survived tail clipping with a titer that most (70\%) transgenic mice can overcome (Figure 4C).

After being directly immunized with rhBDDFVIII with adjuvant once, $2 \mathrm{bF} 8^{\text {trans }}$ mice generated inhibitory antibodies. Platelet FVIII and total platelet numbers in these mice were not significantly different from preimmunization levels (data not shown). All 6 immunized 2bF8 trans mice with an inhibitor titer of $10-50$ $\mathrm{BU} / \mathrm{ml}$ survived tail clipping, and 7 of 9 mice with titers of 51-150 $\mathrm{BU} / \mathrm{ml}$ survived (Figure $4 \mathrm{D}$ ). 

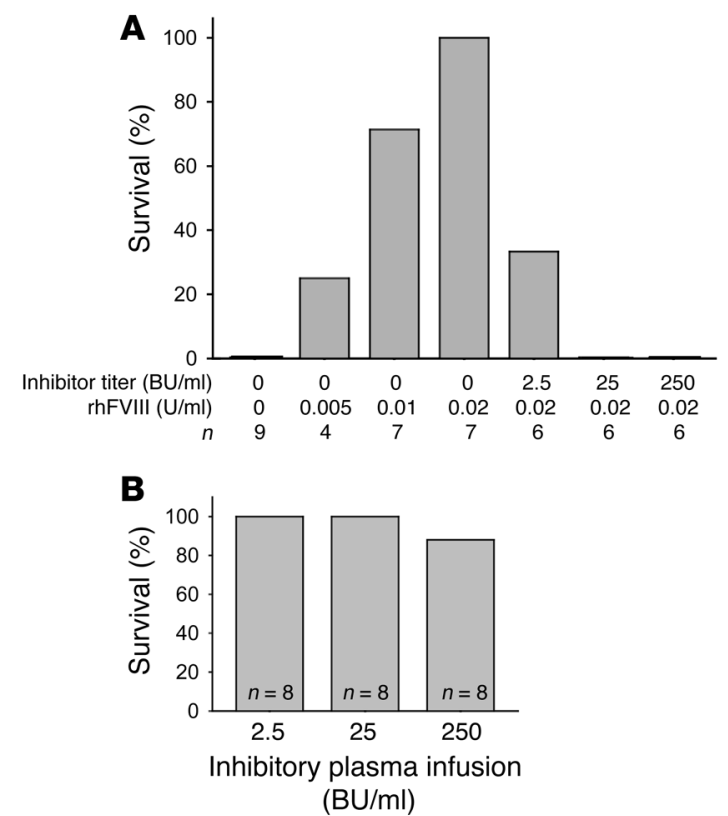

Figure 4

Platelet-derived FVIII can function in the presence of FVIII inhibitory antibodies. (A) Dose response to rhBDDFVIII infusion in FVIIInull mice. When rhBDDFVIII was infused into FVIIInull mice and tail clip was performed, all FVIIInull mice survived tail clipping when infused to a final level of $0.02 \mathrm{U} / \mathrm{ml}$ rhBDDFVIII. When rhBDDFVIII was infused at the same concentration $(0.02$ $\mathrm{U} / \mathrm{ml}$ ) into FVIIInull mice that had been pre-injected with mouse inhibitor plasma, no FVIIInull mice with 25 or $250 \mathrm{BU} / \mathrm{ml}$ survived tail clipping. (B) Dose response to FVIII inhibitory antibody infusion in $2 \mathrm{bF} 8^{\text {trans }}$ mice. Different doses of inhibitor plasma from immunized FVIIInull mice were infused into $2 \mathrm{bF} 8^{\mathrm{tg}+/}$ mice. All mice survived tail clipping when infused with less than $25 \mathrm{BU} / \mathrm{ml}$ inhibitory plasma, and 7 of 8 survived with a titer of $250 \mathrm{BU} / \mathrm{ml}$. (C) Tail clip survival test on the recipients of spleen cell transplantation. Sublethally irradiated $2 \mathrm{bF} 8^{\mathrm{tg}+/}$ or WT mice received spleen cells from immunized FVIIInull mice. Two weeks after transplantation, plasma was tested by inhibitor analysis and the tail clip survival test was performed. Transgenic $2 \mathrm{bF} 8^{\text {trans }}$ mice demonstrated enhanced tail clip survival even in the presence of a titer greater than 5,000 $\mathrm{BU} / \mathrm{ml}$. (D) Tail clip survival test of immunized $2 \mathrm{bF} 8^{\text {trans }}$ mice. Heterozygous $2 \mathrm{bF} 8^{\text {tg }+/}$ mice were immunized with rhBDDFVIII (with adjuvant) by i.p. injection once. Two weeks after immunization, plasma was used for inhibitor quantitation and the tail clip survival test was performed. All immunized $2 \mathrm{bF} 8^{\text {trans }}$ mice survived tail clipping with a titer of $10-50 \mathrm{BU} / \mathrm{ml}$.

We thus demonstrated that expression of FVIII under control of the $\alpha$ IIb promoter maintained efficacy in hemophilia A even in the presence of high-titer inhibitors elicited through 3 different experimental approaches.

\section{Discussion}

While gene therapy for hemophilia A has been attempted in humans, therapeutic levels of FVIII have not yet been achieved (7, 17). This failure may be attributed in part to the fact that none of these approaches directed FVIII synthesis to cells that synthesize and store VWF, even though VWF is known to stabilize FVIII in plasma (40) and in the commercial production of recombinant FVIII products $(41,42)$. FVIII normally circulates in plasma and is not present in platelets or other blood cells $(22,23)$. Our laboratory has previously demonstrated in vitro costorage of FVIII with VWF in megakaryocyte $\alpha$-granules $(22,23)$ and endothelial Weibel-Palade bodies (21) when FVIII is ectopically expressed in these cells, and VWF enhances this expression. Clinically, 25-30\% of hemophilia patients develop inhibitory antibodies in response to FVIII replacement therapy $(43,44)$, and thus gene therapy by con- stitutive synthesis and release of recombinant FVIII into plasma (i.e., specifying gene therapy to liver or endothelial cells) might not be therapeutic in these patients in the presence of such inhibitory antibodies.

We therefore wanted to develop a strategy whereby expressed FVIII is protected from these inactivating antibodies until FVIII is needed to achieve local hemostasis. Such an approach could include patients with FVIII inhibitors as candidates for gene therapy and might be a specific means of long-term treatment of these patients even in the presence of these inhibitors.

We show here that megakaryocytic expression of FVIII was achieved in a transgenic model in which FVIII production is driven by the platelet $\alpha$ IIb promoter. When transgenic 2 bF8 platelet FVIII expression was bred into FVIII ${ }^{\text {null }}$ mice, platelet FVIII was maintained in these mice, yet plasma FVIII remained undetectable. Hemostatic efficacy was demonstrated by normalization of survival following tail clipping in $2 \mathrm{bF} 8^{\text {trans }}$ mice, in marked contrast to the uniform fatality observed in FVIII ${ }^{\text {null }}$ mice. This means that FVIII delivered by the $2 \mathrm{bF} 8^{\text {trans }}$ platelets is provided to sites where it is bioavailable to achieve local hemostatic efficacy.

Our therapeutic approach did not produce detectable plasma FVIII. Three experiments taken together demonstrated that this therapeutic efficacy was restricted to platelet expression of FVIII: (a) confocal immunofluorescent microscopy of peripheral blood using antibodies to human FVIII demonstrated only platelet staining; (b) BMT from $2 b^{2} 8^{\text {trans }}$ mice into lethally irradiated FVIII ${ }^{\text {null }}$ recipients demonstrated maintenance of phenotypic correction with solely hematopoietic expression; and (c) transfusion of platelets from $2 \mathrm{bF}^{\text {trans }}$ mice into FVIII ${ }^{\text {null }}$ mice resulted in correction of the hemorrhagic phenotype, even when only a fraction of the circulating platelets contained FVIII. What fraction of platelets optimally would need to be transduced, and what is the optimal level of FVIII expression per platelet, are questions not yet answered.

While VWF is required for normal plasma levels of FVIII $(20,40)$, we wanted to determine its contribution to transgenic expression of FVIII in platelets. FVIII storage is VWF dependent in AtT-20 cells (4) and endothelial cells $(21,45)$. FVIII colocalizes with VWF when FVIII synthesis is induced in megakaryocytes $(22,23)$. There were therefore 2 issues to study. The first was to determine whether doubling FVIII synthesis would result in greater storage of FVIII. Mice homozygous for the transgene $\left(2 \mathrm{bF}^{\mathrm{tg}^{+/+}}\right)$had significantly increased levels of platelet FVIII, 1.91 times that of the heterozygous $2 \mathrm{bF} 8$ transgenic mice $\left(2 \mathrm{bF} 8^{\mathrm{tg}^{+} /-}\right)$. Second, we wanted to determine whether the storage of FVIII was dependent on the presence of VWF. Studies by Yarovoi and coworkers (46) using a FVIII ELISA immunoassay had previously demonstrated that platelet FVIII antigen, driven by the GPIb promoter, was reduced 
Table 1

\section{Primer sequences}

\begin{tabular}{lcc} 
Primer & Name & Sequence \\
P1 & ahf8 $391-365$ & 5'-AGGCCCTCAGAAGCTTTCCAGTAGGA-3' \\
P2 & pCls $851-874$ & 5'-AGGTAGCCTTGCAGAAGTTGGTCG-3' \\
P3 & shf8 5365-5388 & 5'-ATTCACCCCCAGAGTTGGGTGCA-3' \\
P4 & pCla 2021-1999 & 5'-ATTTCAGGCCATGGTGCTGCGCA-3' \\
P5 & pCls 3371-3392 & 5'-GAATCGATAGCGATAAGGATCC-3' \\
M18-a4743 & a4743-4723 mouse BAC & 5'-ACTGGAGAATTGCAGGAGAT-3' \\
M18-s4536 & s4536-4557 mouse BAC & 5'-GGTCGTGAGCTATCAATGTGAG-3' \\
\hline
\end{tabular}

moter, and reinfused into the patient to provide long-term benefit. This could provide that patient with a self-replicating pool of stem cells that would support lifelong FVIII transgene expression in their megakaryocytes and platelets. A protected releasable FVIII pool in platelets would reduce the bleeding diathesis not only in patients with hemophilia A but also in those with hemophilia A and FVIII inhibitory antibodies. While the latter group has not previously been thought to be candidates for FVIII gene therapy, our present studies suggest a new approach that could be beneficial. by $27 \%$ when bred into the $\mathrm{VWF}^{-/}$- background compared with a WT background. Our studies confirmed that the presence of VWF $\left(\mathrm{VWF}^{+/+}\right.$versus $\mathrm{VWF}^{-/-}$) increased platelet FVIII:C levels with both $2 \mathrm{bF}^{\mathrm{tg} \mathrm{g}^{+/-}}$and $2 \mathrm{bF}^{\mathrm{tg}+/+}$ mice. In the absence of platelet VWF (VWFnull mice), ectopic platelet FVIII expression and storage persisted, but platelet FVIII levels were only $52.7 \%$ and $57.4 \%$ that of the levels in $2 \mathrm{bF}^{\mathrm{tg}+/-}$ and $2 \mathrm{bF}^{\mathrm{tg}+/+}$ mice, respectively, in the presence of VWF (Figure 3C). This implies that in platelets coexpression with VWF is important for optimal FVIII synthesis and/or storage. In contrast to endothelial cells, where Weibel-Palade bodies are not present in the absence of VWF (45), platelet $\alpha$-granules still formed in the absence of VWF and accounted for the continued, but suboptimal, storage of FVIII. Furthermore, having 2 chromosome 18s each with the same transgenic insert resulted in twice the amount of FVIII synthesized and stored in transgenic platelets. We did not find any difference in the specific activity of the FVIII expressed in the presence or absence of VWF (data not shown).

While the phenotypic correction of the hemorrhagic phenotype through ectopic expression of platelet FVIII is in itself an important observation, it is the success of this approach even in the presence of high-titer inhibitory antibodies that is most compelling. Even the development of an inhibitor titer of $2-5 \mathrm{BU} / \mathrm{ml}$ presents a difficult and often expensive challenge to clinical care. This strategy has the potential to offer therapeutic benefit both for hereditary hemophilia A patients with inhibitors and for nonhemophilia A patients with acquired inhibitory antibodies (3, 47, 48) who also have major life-threatening clinical bleeding. As demonstrated in Figure 4A, 100\% of FVIII ${ }^{\text {null }}$ mice infused to as little as $0.02 \mathrm{U} / \mathrm{ml} \mathrm{rhBDDFVIII}$ in plasma survived tail clipping. Low-titer FVIII inhibitory antibodies $(2.5 \mathrm{BU} / \mathrm{ml})$ decrease the survival of transfused FVIII null mice to $33 \%$, and higher titers of inhibitory antibodies (>25 $\mathrm{BU} / \mathrm{ml}$ ) reduced survival rates to $0 \%$ - completely abrogating the benefit of $0.02 \mathrm{U} / \mathrm{ml}$ plasma FVIII infusion.

Because hematopoietic stem cells can both self renew and differentiate into all blood lineages, they are an attractive potential target for gene therapy. Gene transfer into hematopoietic stem cells can potentially provide a cure for many inherited and acquired diseases of the hematopoietic and immune systems (49). FVIII expression has been targeted to the bone marrow with lentiviral vectors using tissue nonspecific promoters, although formation of inhibitors was noticed (10-12). Even if inhibitory antibodies were produced, platelet-expressed FVIII might remain bioavailable and achieve hemostatic efficacy. Such studies are the subject of current investigation. Thus, bone marrow or circulating hematopoietic stem cells could be harvested from hemophilia A patients, transduced or transfected with an expression cassette for FVIII driven by a platelet-specific pro-

\section{Methods}

Construction of vector. The human FVIII cDNA used in this study has the entire FVIII B-domain deleted and was a kind gift of R.J. Kaufman (University of Michigan, Ann Arbor, Michigan, USA). hBDDFVIII was excised from the PMT2 vector (50) by XhoI and SalI and used to create pIIb-BDDFVIIIneo vector as described in our previous study (22). PvuI and RsrII sites were introduced at the beginning of the $\alpha \mathrm{IIb}$ promoter in PIIb-BDDFVIIIneo by PCR mutagenesis. The resulting vector, PIIb-BDDFVIIIneo (PvuI), was used to release the $2 \mathrm{bF} 8$ expression cassette for generating transgenic mice.

Generation of transgenic mice. Studies were approved by the Animal Care and Use Committee of the Medical College of Wisconsin. Transgenic mice were generated in the Transgenic Core Facility of the Medical College of Wisconsin and Blood Research Institute. A 7.6-kb fragment, containing the $\alpha I I b$ promoter, $\beta$-globin/IgG chimeric intron, hBDDFVIII, SV40 Poly A, and a neomycin resistance cassette, was electroporated into 129S ES cells. Colonies were selected using G418 and screened for the presence of the transgene using the PCR strategy shown in Figure 1A and detailed in Table 1 using primers $\mathrm{P} 1-\mathrm{P} 4$ specific for the $2 \mathrm{bF} 8$ transgene. Transgene-positive ES cells were propagated for microinjection into blastocysts to generate chimeric mice carrying the transgene, and 2bF8 transgene was then bred into the exon 17 FVIII knockout background (51). Genotype determination was performed by PCR analysis of blood-derived genomic DNA samples using primers as described above.

Insertion location analysis. The insertion position of the $2 \mathrm{bF} 8$ transgene was determined by DNA Walking PCR using DNA Walking SpeedUp kit (Seegene) per the manufacturer's instructions. A BLAST search of Gene Bank identified the insertion site on chromosome 18 after base 4667 of BAC clone RP23-127 B9. A pair of primers, M18-a4743 and M18-s4536 (Table 1), flanking the putative insertion site were designed to confirm disruption of the insertion locus in transgene positive animals.

Generation of $2 b F 8$ homozygous and $2 b F 8^{\text {trans } V W F u l l ~ m i c e . ~ H o m o z y g o u s ~}$ $2 \mathrm{bF} 8^{\text {trans }}$ mice were generated from heterozygous mating. Genotype was determined by PCR using primer P5 or primers M18-a4743 and M18-s4536 (Table 1 and Figure 1). Furthermore, mating 2bF8 $8^{\text {trans }}$ mice with VWFrnull mice (20) generated $2 \mathrm{bF}^{\text {trans } V W F}{ }^{\text {null }}$ mice. VWF ${ }^{\text {null }}$ mice were identified by means of a solid phase capture ELISA of mouse plasma, using rabbit antihuman VWF that crossreacts with murine VWF (Dako) as a capture Ab and HRP-labeled VWF Ab for detection.

FVIII:C assays. FVIII:C levels in mouse plasma and platelet lysate or releasate were quantitated by a modified FVIII chromogenic assay that we have developed using the Coatest VIII:C/4 Kit (DiaPharm) as previously described $(21,23)$. One hundred microliters of blood was collected by tail bleeding in tubes containing $0.1 \mathrm{vol}$ of $0.1 \mathrm{M}$ sodium citrate. Cells were removed by centrifugation at $960 \mathrm{~g}$ for 20 minutes, and the platelet poor plasma was tested for plasma FVIII:C.

For platelet lysate or releasate assay, platelets were separated using Fico/ Lite-Platelets (Atlanta Biologicals) from $200 \mu \mathrm{l}$ blood with $50 \mathrm{ng} / \mathrm{ml}$ of 
prostaglandin E1 (Sigma-Aldrich). Separated platelets were washed with PBS containing 2 mM EDTA (Sigma-Aldrich) and 0.5\% BSA (Invitrogen), counted with an Animal Blood Counter (Heska), and centrifuged at $960 \mathrm{~g}$ for 20 minutes. The platelet pellet was lysed in $200 \mu \mathrm{l}$ of $0.5 \% 3$-[(3-chol amidopropyl)dimethylammonio]-1-propanesulfonate (CHAPS, the zwitterionic detergent; MP Biomedicals) by vortex until suspended, incubated on ice for 10 minutes, and spun down at $20,800 \mathrm{~g}$ at $4^{\circ} \mathrm{C}$ for 10 minutes. The supernatant was then assayed for FVIII:C.

For the platelet releasate assay, fresh platelets were resuspended in 150 $\mu 1$ modified Tyrode's buffer (20 mM HEPES, $137 \mathrm{mM} \mathrm{NaCl}, 13.8 \mathrm{mM}$ $\mathrm{NaHCO}_{3}, 0.36 \mathrm{mM} \mathrm{NaH}_{2} \mathrm{PO}_{4}, 2.5 \mathrm{mM} \mathrm{KCl}, 1 \mathrm{mM} \mathrm{MgCl}_{2}, 5.5 \mathrm{mM}$ glucose, and $0.25 \% \mathrm{BSA}$ ) containing $1 \mathrm{mM} \mathrm{CaCl}, 2 \mu \mathrm{M} \mathrm{ADP}$ (Chrono-log Corporation), and $25 \mu \mathrm{M}$ each of epinephrine (BIO/DATA Corporation) and the murine thrombin receptor activation peptide (GYPGKF-NH $\mathrm{N}_{2}$, synthesized by our core laboratory), incubated at room temperature for 30 minutes, and then centrifuged at $20,800 \mathrm{~g}$ at $4^{\circ} \mathrm{C}$ for 10 minutes. The resulting supernatant was used for the assay of released FVIII:C.

Mouse plasma was diluted at 1:40 in modified Tyrode's buffer, and $25 \mu \mathrm{l}$ of diluted plasma, platelet releasate, or serially diluted platelet lysate were added to blocked 96-well microtiter plates in triplicate. Assay components, including FIXa, $\mathrm{FX}, \mathrm{CaCl}_{2}$, and phospholipid were added to each well, and the plates were incubated for 10 minutes at $37^{\circ} \mathrm{C}$. The chromogenic Factor Xa substrate S-2222 was added, and the plate was transferred immediately to a ThermoMax microplate reader (Molecular Devices) preset at $37^{\circ} \mathrm{C}$. A standard curve was constructed by plotting known amounts of rhBDDFVIII (Refacto; Wyeth) in the appropriate buffer against $V_{\max }(\mathrm{mOD} / \mathrm{min})$ at 405 $\mathrm{nm}$. The $V_{\max }$ of each reaction was converted to units of FVIII:C $(\mathrm{U} / \mathrm{ml})$ using the instrument manufacturer's software program (SoftMax version 2.34; Molecular Devices), and the data were averaged. Platelets from WT and FVIIInull mice served as controls in the platelet releasate or lysate assays. FVIII:C in mononuclear cell lysate was similarly determined.

Immunostaining for hBDDFVIII. Visual detection of hBDDFVIII in transgenic platelets was accomplished with immunofluorescent- or immunogold-labeled antibody and confocal laser scanning microscopy or EM. Controls (platelets from FVIII ${ }^{\text {null }}$ mice) were processed in parallel with each immunostaining assay under the same conditions.

For confocal studies, cells were spun onto glass slides, fixed using 3.7\% (vol/vol) buffered formalin, permeabilized with $5 \%$ Triton X-100, and blocked in $2.5 \%$ normal goat serum in HBSS (Invitrogen) for 1 hour. Cells were incubated in primary antibody at $4{ }^{\circ} \mathrm{C}$ overnight. Rabbit polyclonal antibody against human FVIII (Conan; generated by our laboratory) was directly conjugated to AlexaFluor 488 (Invitrogen) and rabbit antibody to VWF (Dako) was conjugated to AlexaFluor 568. Nonspecific isotype control antibodies served as negative controls. Cells were mounted under glass coverslips with Vectashield. Immunofluorescent detection was performed by confocal microscopy using a Leica TCS SP2 Confocal Laser Imaging System (Leica Microsystems).

For EM studies, isolated platelets were washed in modified Tyrode's buffer and centrifuged at $960 \mathrm{~g}$ for 20 minutes at room temperature. The pellet was fixed in $0.25 \%$ glutaraldehyde plus $4 \%$ paraformaldehyde and $0.2 \%$ (wt/ vol) picric acid in $0.1 \mathrm{M}$ phosphate buffer, $\mathrm{pH} 7.3$, on ice for 1 hour. The fixed cell pellets were processed using the enhanced membrane contrast technique (52) and embedded in Lowicryl K4M resin using a previously reported protocol (53). Ultrathin sections (60 nm thick) were collected on formvar/carbon-coated copper grids. All incubations were carried out on 25- $\mu$ l droplets on parafilm in a humidified chamber. Sections were incubated with anti-Factor VIII mAb, 103.3, or anti-VWF polyclonal Ab (Dako) and then probed with goat anti-mouse $(5 \mathrm{~nm})$ and goat anti-rabbit $(10 \mathrm{~nm})$ colloidal gold probes, respectively. The sections were observed in a Hitachi H600 TEM (Hitachi High-Technologies) operating at $75 \mathrm{kV}$.
Phenotype correction analysis. Phenotypic correction was assessed by the tail clip survival test as previously described (54-56). The tails of 8- to 16week-old anesthetized mice were clipped at a diameter of $1.59 \mathrm{~mm}$, without subsequent cauterization. Clot formation and survival beyond 24 hours was used to indicate correction of the murine hemophilia A phenotype.

$2 b F 8^{\text {trans }} B M T$. Anesthetized mice were sacrificed by cervical dislocation, and bone marrow was harvested by flushing the femurs and tibias as previously described (23). Mononuclear cells were isolated with Fico/Lite-LM (mouse; Atlanta Biologicals), washed with cold PBS containing EDTA and BSA, and resuspended in PBS (Invitrogen) for transplantation.

Six- to 8-week-old FVIII ${ }^{\text {null }}$ mice (recipients) were conditioned for cellular transplantation with a lethal dose of $1100 \mathrm{cGy}$ total body irradiation using a cesium irradiator (23). Twenty-four hours after irradiation, a cell dose of $8-10 \times 10^{6}$ cells from heterozygous $2 \mathrm{bF} 8^{\text {trans }}$ mice in a volume of $200-300 \mu \mathrm{l} /$ mouse was infused by retroorbital injection. The recipients were analyzed after allowing 3 weeks for bone marrow reconstitution. At 4 months, a sequential BMT was performed from these transplanted mice into additional irradiated FVIIInull mice. As a control, bone marrow mononuclear cells from FVIIInull mice were transplanted into lethally irradiated littermates with the same cell dose.

Evaluation of the efficacy of platelet-derived FVIII in the presence of antiFVIII inhibitory antibodies. FVIIInull mice were immunized with $200 \mu \mathrm{l}$ of rhBDDFVIII at $600 \mathrm{U} / \mathrm{kg}$ in the presence of adjuvant (Corixa) by i.p. injection to induce anti-human FVIII antibodies. To determine the titer of inhibitors, a modified Bethesda assay was performed. Sequential dilution of immunized mouse plasma was incubated with an equal volume of $1 \mathrm{U} / \mathrm{ml} \mathrm{rhBDDFVIII}$ at $37^{\circ} \mathrm{C}$ for 2 hours, and residual FVIII:C was subsequently analyzed by chromogenic assay. BU were defined by dilution of the blood plasma until 50\% of the initial FVIII was neutralized (39).

In the acute model, mouse plasma from immunized FVIII ${ }^{\text {null }}$ mice containing FVIII inhibitory antibodies was infused into heterozygous $2 \mathrm{bF}^{\text {trans }}$ mice by retroorbital injection. One hour after infusion, blood was collected and plasma was assayed for inhibitors. The tail clip survival test was performed to determine whether the platelet-derived FVIII could still be therapeutically effective in the presence of inhibitors. As controls, FVIII ${ }^{\text {null }}$ mice that had been preinjected with mouse inhibitor plasma or control plasma were infused with $0.02 \mathrm{U} / \mathrm{ml} \mathrm{rhBDDFVIII}$, and tail clip was performed.

In the chronic model, spleen cells from immunized FVIII ${ }^{\text {null }}$ mice were transplanted into sublethally irradiated heterozygous $2 \mathrm{bF}^{\text {trans }}$ mice. Spleens from immunized FVIII ${ }^{\text {null }}$ mice were ground up, and red cells were lysed with Red Cell Lysing buffer (Sigma-Aldrich). Cells were washed and resuspended in PBS (Invitrogen) at $1 \times 10^{8}$ cells $/ \mathrm{ml}$ for transplantation. Eight- to 10 -week-old $2 \mathrm{bF}^{\text {trans }}$ mice were conditioned for cellular transplantation with a sublethal dose of $400 \mathrm{cGy}$ total body irradiation. Twentyfour hours after irradiation, a cell do se of $2-3 \times 10^{7}$ cells from immunized FVIII ${ }^{\text {null }}$ spleen in a volume of $200-300 \mu \mathrm{l} /$ mouse was infused by retroorbital injection. As a control, the same cell dose was transplanted into conditioned WT mice that contained normal mouse FVIII. Two weeks after transplantation, blood was collected, and cell number was counted with an Animal Blood Counter. Plasma was tested by inhibitor analysis, and the tail clip survival test was performed to determine phenotypic correction.

A second chronic model was developed and involved immunizing heterozygous $2 \mathrm{bF}^{\text {trans }}$ mice with rhBDDFVIII at $600 \mathrm{U} / \mathrm{kg}$ given with adjuvant by i.p. injection. Two weeks after immunization, blood was collected and cell number was determined with the Animal Blood Counter. Plasma was used for inhibitor analysis, and platelets were used for platelet lysate FVIII:C assay. The tail clip survival test was performed to determine phenotypic correction.

Statistics. All FVIII:C results are presented as mean \pm SD, and the significance of differences was evaluated by 2 -tailed Student's $t$ test. A value of $P<0.05$ was considered statistically significant. 


\section{Acknowledgments}

We acknowledge the technical assistance of S. Kalloway, M. Kipp, J.Foeckler, and D. Reimesch (Transgenic Core Facility) in the generation of transgenic animals. We thank H. Kazazian (University of Pennsylvania School of Medicine, Philadelphia, Pennsylvania, USA) for the FVIII ${ }^{\text {null }}$ mice. The VWF ${ }^{\text {null }}$ mice were developed by D. Wagner at Harvard Medical School and purchased from Jackson Laboratory. This work was supported by NIH grants HL 44612 and HL 33721 (to R.R. Montgomery), HL 68138 (to D.A. Wilcox), and HL 44612-14 (to H. Weiler); by American Heart Association grants $0320043 Z$ and $0520035 Z$ (to Q. Shi); and by Children's Hospital Foundation (to Q. Shi).

Received for publication March 6, 2006, and accepted in revised form April 18, 2006.

Address correspondence to: Robert R. Montgomery, Blood Research Institute, BloodCenter of Wisconsin, 8701 Watertown Plank Road, Milwaukee, Wisconsin 53226, USA. Phone: (414) $937-$ 3802; Fax: (414) 937-6811; E-mail: bob.montgomery@bcw.edu.
1. Kaufman, R.J. 1999. Advances toward gene therapy for hemophilia at the millennium. Hum. Gene Ther. 10:2091-2107.

2. Furie, B., Limentani, S.A., and Rosenfield, C.G. 1994. A practical guide to the evaluation and treatment of hemophilia. Blood. 84:3-9.

3. Scandella, D.H. 2000. Properties of anti-factor VIII inhibitor antibodies in hemophilia A patients. Semin. Thromb. Hemost. 26:137-142.

4. Rosenberg, J.B., et al. 1998. Intracellular trafficking of factor VIII to von Willebrand factor storage granules. J. Clin. Invest 101:613-624.

5. Do, H., Healey, J.F., Waller, E.K., and Lollar, P. 1999. Expression of factor VIII by murine liver sinusoidal endothelial cells. J. Biol. Chem. 274:19587-19592.

6. High, K.A. 2003. Gene transfer as an approach to treating hemophilia. Semin. Thromb. Hemost. 29:107-120.

7. Roth, D.A., Tawa, N.E., Jr., O’Brien, J.M., Treco, D.A., and Selden, R.F. 2001. Nonviral transfer of the gene encoding coagulation factor VIII in patients with severe hemophilia A. N. Engl. J. Med. 344:1735-1742.

8. Saenko, E.L., Ananyeva, N.M., Moayeri, M., Ramezani, A., and Hawley, R.G. 2003. Development of improved factor VIII molecules and new gene transfer approaches for hemophilia A. Curr. Gene Ther. 3:27-41.

9. Yarovoi, H.V., et al. 2003. Factor VIII ectopically expressed in platelets: efficacy in hemophilia A treatment. Blood. 102:4006-4013.

10. Kootstra, N.A., Matsumura, R., and Verma, I.M. 2003. Efficient production of human FVIII in hemophilic mice using lentiviral vectors. Mol. Ther. 7:623-631.

11. Tiede, A., et al. 2003. Recombinant factor VIII expression in hematopoietic cells following lentiviral transduction. Gene Ther. 10:1917-1925.

12. Moayeri, M., Ramezani, A., Morgan, R.A., Hawley, T.S., and Hawley, R.G. 2004. Sustained phenotypic correction of hemophilia a mice following oncoretroviral-mediated expression of a bioengineered human factor VIII gene in long-term hematopoietic repopulating cells. Mol. Ther. 10:892-902.

13. Ye, P., et al. 2004. Naked DNA transfer of Factor VIII induced transgene-specific, species-independent immune response in hemophilia A mice. $\mathrm{Mol}$. Ther. 10:117-126.

14. Xu, L., et al. 2005. Absence of a desmopressin response after therapeutic expression of factor VIII in hemophilia A dogs with liver-directed neonatal gene therapy. Proc. Natl. Acad. Sci. U. S. A. 102:6080-6085.

15. Scallan, C.D., et al. 2003. Phenotypic correction of a mouse model of hemophilia A using AAV2 vectors encoding the heavy and light chains of FVIII. Blood. 102:3919-3926.

16. Kelley, K., Verma, I., and Pierce, G.F. 2002. Gene therapy: reality or myth for the global bleeding disorders community? Haemophilia. 8:261-267.

17. Powell, J.S., et al. 2003. Phase 1 trial of FVIII gene transfer for severe hemophilia A using a retroviral construct administered by peripheral intravenous infusion. Blood. 102:2038-2045.

18. Chuah, M.K., Collen, D., and VandenDriessche, T. 2004. Clinical gene transfer studies for hemophilia A. Semin. Thromb. Hemost. 30:249-256.

19. Kaufman, R.J., Wasley, L.C., and Dorner, A.J. 1988. Synthesis, processing, and secretion of recombinant human factor VIII expressed in mammalian cells. J. Biol. Chem. 263:6352-6362.

20. Denis, C., et al. 1998. A mouse model of severe von Willebrand disease: defects in hemostasis and thrombosis. Proc. Natl. Acad. Sci. U. S. A. 95:9524-9529.

21. Rosenberg, J.B., Greengard, J.S., and Montgomery, R.R. 2000. Genetic induction of a releasable pool of factor VIII in human endothelial cells. Arterioscler. Thromb. Vasc. Biol. 20:2689-2695.

22. Shi, Q., Wilcox, D.A., Fahs, S.A., Kroner, P.A., and Montgomery, R.R. 2003. Expression of human factor VIII under control of the platelet-specific alphaIIb promoter in megakaryocytic cell line as well as storage together with VWF. Mol. Genet. Metab. 79:25-33.

23. Wilcox, D.A., et al. 2003. Induction of megakaryocytes to synthesize and store a releasable pool of human factor VIII. J. Thromb. Haemost. 1:2477-2489.

24. Nachman, R., Levine, R., and Jaffe, E.A. 1977. Synthesis of factor VIII antigen by cultured guinea pig megakaryocytes. J. Clin. Invest. 60:914-921.

25. Sprandio, J.D., Shapiro, S.S., Thiagarajan, P., and McCord, S. 1988. Cultured human umbilical vein endothelial cells contain a membrane glycoprotein immunologically related to platelet glycoprotein Ib. Blood. 71:234-237.

26. Konkle, B.A., Shapiro, S.S., Asch, A.S., and Nachman, R.L. 1990. Cytokine-enhanced expression of glycoprotein Ib alpha in human endothelium. J. Biol. Chem. 265:19833-19838.

27. Rajagopalan, V., Essex, D.W., Shapiro, S.S., and Konkle, B.A. 1992. Tumor necrosis factor-alpha modulation of glycoprotein Ib alpha expression in human endothelial and erythroleukemia cells. Blood. 80:153-161.

28. Oleksowicz, L., Dutcher, J.P., DeLeon-Fernandez, M., Paietta, E., and Etkind, P. 1997. Human breast carcinoma cells synthesize a protein immunorelated to platelet glycoprotein-Ib alpha with different functional properties. J. Lab. Clin. Med. 129:337-346.

29. Wilcox, D.A., Olsen, J.C., Ishizawa, L., Griffith, M., and White, G.C. 1999. Integrin alphaIIb promotertargeted expression of gene products in megakaryocytes derived from retrovirus-transduced human hematopoietic cells. Proc. Natl. Acad. Sci. U. S. A. 96:9654-9659.

30. Rodriguez, M.H., et al. 2002. Expression of coagulation factor IX in a haematopoietic cell line. Thromb. Haemost. 87:366-373.

31. Berridge, M.V., Ralph, S.J., and Tan, A.S. 1985. Cell-lineage antigens of the stem cell-megakaryocyte-platelet lineage are associated with the platelet IIb-IIIa glycoprotein complex. Blood. 66:76-85.

32. Phillips, D.R., Charo, I.F., Parise, L.V., and Fitzger- ald, L.A. 1988. The platelet membrane glycoprotein IIb-IIIa complex. Blood. 71:831-843.

33. Uzan, G., Prandini, M.H., and Berthier, R. 1995. Regulation of gene transcription during the differentiation of megakaryocytes. Thromb. Haemost. 74:210-212.

34. Block, K.L., and Poncz, M. 1995. Platelet glycoprotein IIb gene expression as a model of megakaryocyte-specific expression. Stem Cells. 13:135-145.

35. Tronik-Le, R.D., Roullot, V., Schweitzer, A., Berthier, R., and Marguerie, G. 1995. Suppression of erythro-megakaryocytopoiesis and the induction of reversible thrombocytopenia in mice transgenic for the thymidine kinase gene targeted by the platelet glycoprotein alpha IIb promoter. J. Exp. Med. 181:2141-2151.

36. Tropel, P., et al. 1997. A $2.7-\mathrm{kb}$ portion of the 5 ' flanking region of the murine glycoprotein alphaIIb gene is transcriptionally active in primitive hematopoietic progenitor cells. Blood. 90:2995-3004.

37. Fang, J., et al. 2005. Therapeutic expression of the platelet-specific integrin, alphaIIbbeta3, in a murine model for Glanzmann thrombasthenia. Blood. 106:2671-2679.

38. Shi, Q., et al. 2004. Targeting platelet GPIbalpha transgene expression to human megakaryocytes and forming a complete complex with endogenous GPIbbeta and GPIX. J. Thromb. Haemost. 2:1989-1997.

39. Verbruggen, B., et al. 1995. The Nijmegen modification of the Bethesda assay for factor VIII:C inhibitors: improved specificity and reliability. Thromb. Haemost. 73:247-251.

40. Wagner, D.D. 1990. Cell biology of von Willebrand factor. Annu. Rev. Cell Biol. 6:217-246.

41. Pittman, D.D., et al. 1993. Biochemical, immunological, and in vivo functional characterization of B-domain-deleted factor VIII. Blood. 81:2925-2935.

42. Thomas, K.B., et al. 1999. Continuous infusion of FVIII and FIX concentrates: in vitro analysis of clinically relevant parameters. Haemophilia. 5:17-25.

43. Yoshioka, A., Fukutake, K., Takamatsu, J., and Shirahata, A. 2003. Clinical evaluation of a recombinant factor VIII preparation (Kogenate) in previously untreated patients with hemophilia A. Int. J. Hematol. 78:467-474.

44. Gringeri, A., et al. 2004. Efficacy and inhibitor development in previously treated patients with haemophilia A switched to a B domain-deleted recombinant factor VIII. Br. J. Haematol. 126:398-404.

45. Haberichter, S.L., et al. 2005. Re-establishment of VWF-dependent Weibel-Palade bodies in VWD endothelial cells. Blood. 105:145-152.

46. Yarovoi, H., Nurden, A.T., Montgomery, R.R., Nurden, P., and Poncz, M. 2005. Intracellular interaction of von Willebrand factor and factor VIII depends on cellular context: lessons from plateletexpressed factor VIII. Blood. 105:4674-4676.

47. Wendell, C.M., Bellazzini, M.A., and Howes, D.S 2004. Acquired factor VIII inhibitor presenting as a tongue hematoma. J. Emerg. Med. 26:411-414.

48. Moraca, R.J., and Ragni, M.V. 2002. Acquired anti- 
FVIII inhibitors in children. Haemophilia. 8:28-32. 49. Nathwani, A.C., Davidoff, A.M., and Linch, D.C. 2005. A review of gene therapy for haematological disorders. Br. J. Haematol. 128:3-17.

50. Pittman, D.D., Marquette, K.A., and Kaufman, R.J. 1994. Role of the B domain for factor VIII and factor $\mathrm{V}$ expression and function. Blood. 84:4214-4225

51. Bi, L., et al. 1995. Targeted disruption of the mouse factor VIII gene produces a model of hae- mophilia A. Nat. Genet. 10:119-121.

52. Berryman, M.A., and Rodewald, R.D. 1990 An enhanced method for post-embedding immunocytochemical staining which preserves cell membranes. J. Histochem. Cytochem. 38:159-170.

53. Burleigh, B.A., Wells, C.W., Clarke, M.W., and Gardiner, P.R. 1993. An integral membrane glycoprotein associated with an endocytic compartment of Trypanosoma vivax: identification and partial characterization. J. Cell Biol. 120:339-352.
54. Connelly, S., et al. 1998. Sustained phenotypic correction of murine hemophilia $\mathrm{A}$ by in vivo gene therapy. Blood. 91:3273-3281.

55. Fakharzadeh, S.S., Zhang, Y., Sarkar, R., and Kazazian, H.H., Jr. 2000. Correction of the coagulation defect in hemophilia A mice through factor VIII expression in skin. Blood. 95:2799-2805.

56. Parker, E.T., and Lollar, P. 2003. A quantitative measure of the efficacy of factor VIII in hemophilia A mice. Thromb. Haemost. 89:480-485. 